\title{
Optimisation of cholesterol management
}

Singapore Med J 2013; 54(6): 359 doi: 10.11622/smedj.2013131

I congratulate Aung et al on their recently published article, "Public perceptions, knowledge and awareness of cholesterol management in Singapore: a prospective pilot study".(1) There are three aspects worth considering.

Firstly, I agree with the authors that in order to ensure efficient cholesterol management and good patient compliance, there is an urgent need to improve communication and interaction between physicians and patients. Among other things, it would therefore be desirable for each patient to receive comprehensive information from the physician concerning primary and secondary prevention of atherosclerosis, regardless of the reason for contact between the doctor and patient. ${ }^{(2)}$

Secondly, numerous studies have shown that, in practice, the intended therapeutic cholesterol targets are only reached among a minority group. ${ }^{(3,4)}$ This is also the case in Singapore. ${ }^{(5)}$ In addition to the proven lack of public awareness regarding the danger of hypercholesterolaemia, financial restrictions in prescription policy also impede the practical implementation of adequate therapy, especially where secondary prevention of cardiovascular diseases is concerned. Paradoxically, the long-term economic benefits of efficient cholesterol management are often disregarded in this context. ${ }^{(2)}$

Thirdly, in order to achieve optimised, far-reaching cholesterol management, there is a particular need for further setting-related encouragement of periodically recurring mass media information campaigns, as well as timely application of extensive prevention measures (including dietary changes, weight reduction and increased physical activity) in the general public, with all of the stakeholder groups being taken into account. ${ }^{(2,5,6)}$

Finally, I think that as an additional part of lifestyle modification, more volitional intervention strategies (e.g. self-observation training) aimed at enhancing competence in implementation planning and intention shielding should be implemented.

Yours sincerely,

Martin Hofmeister

Consumer Centre of the German Federal State of Bavaria, Department Food and Nutrition, Mozartstraße 9, D-80336 Munich, Germany. hofmeister@vzbayern.de

\section{REFERENCES}

1. Aung TH, Go YY, Low LP, Chua T. Public perceptions, knowledge and awareness of cholesterol management in Singapore: a prospective pilot study. Singapore Med J 2013; 54:32-5.

2. Darioli R, Meier B, Noll G. [A request for improvement of cholesterol management]. Cardiovascular Medicine 2009; 12:151-9. German.

3. Assmann G, Benecke H, Neiss A, et al. Gap between guidelines and practice: attainment of treatment targets in patients with primary hypercholesterolemia starting statin therapy. Results of the 4E-Registry (efficacy calculation and measurement of cardiovascular and cerebrovascular events including physicians' experience and evaluation). Eur J Cardiovasc Prev Rehabil 2006; 13:776-83.

4. Park JE, Chiang CE, Munawar M, et al. Lipid-lowering treatment in hypercholesterolaemic patients: the CEPHEUS Pan-Asian survey. Eur J Prev Cardiol 2012; 19:781-94.

5. Ho KT, Chin KW, Ng KS, et al. The A-SACT (Achievement in Singapore of Cholesterol Targets) study in patients with coronary heart disease. Am J Cardiovasc Drugs 2006; 6:383-91.

6. Mannu GS, Zaman MJ, Gupta A, Rehman HU, Myint PK. Evidence of lifestyle modification in the management of hypercholesterolemia. Curr Cardiol Rev $2013 ; 9: 2-14$. 